\title{
High modulated soliton power propagation interaction with optical fiber and optical wireless communication channels
}

\author{
Mahmoud M. A. Eid ${ }^{1}$, Ashraf S. Seliem², Ahmed Nabih Zaki Rashed ${ }^{3}$, Abd El-Naser A. Mohammed ${ }^{4}$, \\ Mohamed Yassin $\mathrm{Ali}^{5}$, and Shaimaa S. Abaza ${ }^{6}$ \\ ${ }^{1}$ Department of Electrical Engineering, College of Engineering, Taif University, Kingdom of Saudi Arabia \\ ${ }^{3,4}$ Electronics and Electrical Communications Engineering Department, Faculty of Electronic Engineering, Menoufia \\ University, Egypt \\ ${ }^{2,5,6}$ Benha Faculty of Engineering, Benha University, Benha, Egypt
}

\begin{tabular}{|c|c|}
\hline Article Info & ABSTRACT \\
\hline $\begin{array}{l}\text { Article history: } \\
\text { Received Aug 14, } 2020 \\
\text { Revised Nov 29, } 2020 \\
\text { Accepted Dec 11, } 2020\end{array}$ & $\begin{array}{l}\text { This paper has presented high modulated soliton power transmission interaction } \\
\text { with optical fiber and optical wireless communication channels at flow rate of } 40 \\
\text { Gbps and } 20 \mathrm{~km} \text { link range. The proposed modulation schemes are continuous } \\
\text { phase frequency shift keying (CPFSK), Quadrature amplitude modulation } \\
\text { (QAM), differential phase shift keying (DPSK), frequency shift keying (FSK), } \\
\text { pulse amplitude modulation (PAM), minimum shift keying (MSK), and optical }\end{array}$ \\
\hline $\begin{array}{l}\text { Keywords: } \\
\text { Fiber channel } \\
\text { High soliton power } \\
\text { Modulation schemes } \\
\text { Wireless channel }\end{array}$ & $\begin{array}{l}\text { performance than other proposed modulation schemes for both optical fiber and } \\
\text { optical wireless communication channels. The enhancement of optical } \\
\text { signal/noise ratio at fiber/wireless channel, received electrical power and } \\
\text { signal/noise ratio at optical receiver with increase of bits per symbol for different } \\
\text { proposed modulation schemes except for CPFSK scheme. Therefore it is evident } \\
\text { that CPFSK modulation scheme is more efficient and better performance than } \\
\text { other modulation schemes for different communication channels. The obtained } \\
\text { results are simulated with optisystem program version } 13 \text {. }\end{array}$ \\
\hline
\end{tabular}

This is an open access article under the CC BY-SA license.

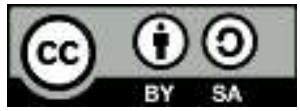

Corresponding Author:

Ahmed Nabih Zaki Rashed

Faculty of Electronic Engineering

Menouf, Menoufia University, Egypt

E-mail: ahmed_733@yahoo.com

\section{INTRODUCTION}

They have outlined the soliton molecule concept. The output field amplitude for two, three soliton molecules are measured in the presence of spatial light modulator [1-9]. The Soliton transmission performance in optical wired link is investigated in the presence of nonlinear conditions and micro ring resonators [10-15]. They have reviewed optical soliton pulses in the nonlinear effects. Bit error rate is measured for free space optics channel for $2.5 \mathrm{~Gb} / \mathrm{s}$ transmission [3]. They have presented the analysis of high order soliton interaction effects on fiber channel [16-22]. They have examined femto-second Soliton transmission in erbium doped fiber amplifiers media. They have found Inhomogeneous Hirota Maxwell Bloch equation for solving the exact soliton managed for dispersion control with the variations of nonlinear effects parameters and dispersion parameter effects [23-26]. They have also discussed the effect of amplified periodic pulse distribution and soliton pulse compression when they have into account the soliton signal stability in special cases [27-37]. They have reviewed the soliton order propagation system for ultra high system transmission capacity for possible transmission bit rate of $80 \mathrm{~Gb} / \mathrm{s}$ for possible transmission length of $20000 \mathrm{~km}$. operating signal wavelengths that are available are $1300 \mathrm{~nm}, 1550 \mathrm{~nm}$ [38-45]. 


\section{MODEL DESCRIPTION}

Figure 1 outlines the view of proposed model for this study. Pseudo random bit sequence generator generates sequence of bits usually bit sequence of 0 's and 1's. The generated bit sequence is directed to electrical modulators and optical Sech pulse generators for modulating and reshaping soliton pulses with high power level of $2 \mathrm{~W}$, and operating frequency of $1550 \mathrm{~nm}$. The modulated electrical signal from electrical modulators and high optical soliton signal power are directed to electro optic modulator such as Mach Zehnder modulator for modulating the electro optic signal. The modulated optical signal is then distributed through fork element to two path, one is optical fiber channel and the second is optical wireless communication channel. The two optical signal are then directed to APD to convert the optical signal to light signal. The converted electrical signal directed to low pass bessel filter (LPBF) in order to removed unwanted signal from the original signal. The output signal from LPBF is then forward to $3 \mathrm{R}$ regenerator for retiming, regeneration and reshaping.

WDM analyzer measures signal power, noise power, gain, noise figure, and optical signal/noise ratio for both fiber/wireless communication channel. Eye diagram analyzer tests the max $\mathrm{Q}$ factor level, signal/noise ratio and min bit error rate at the receiver side.

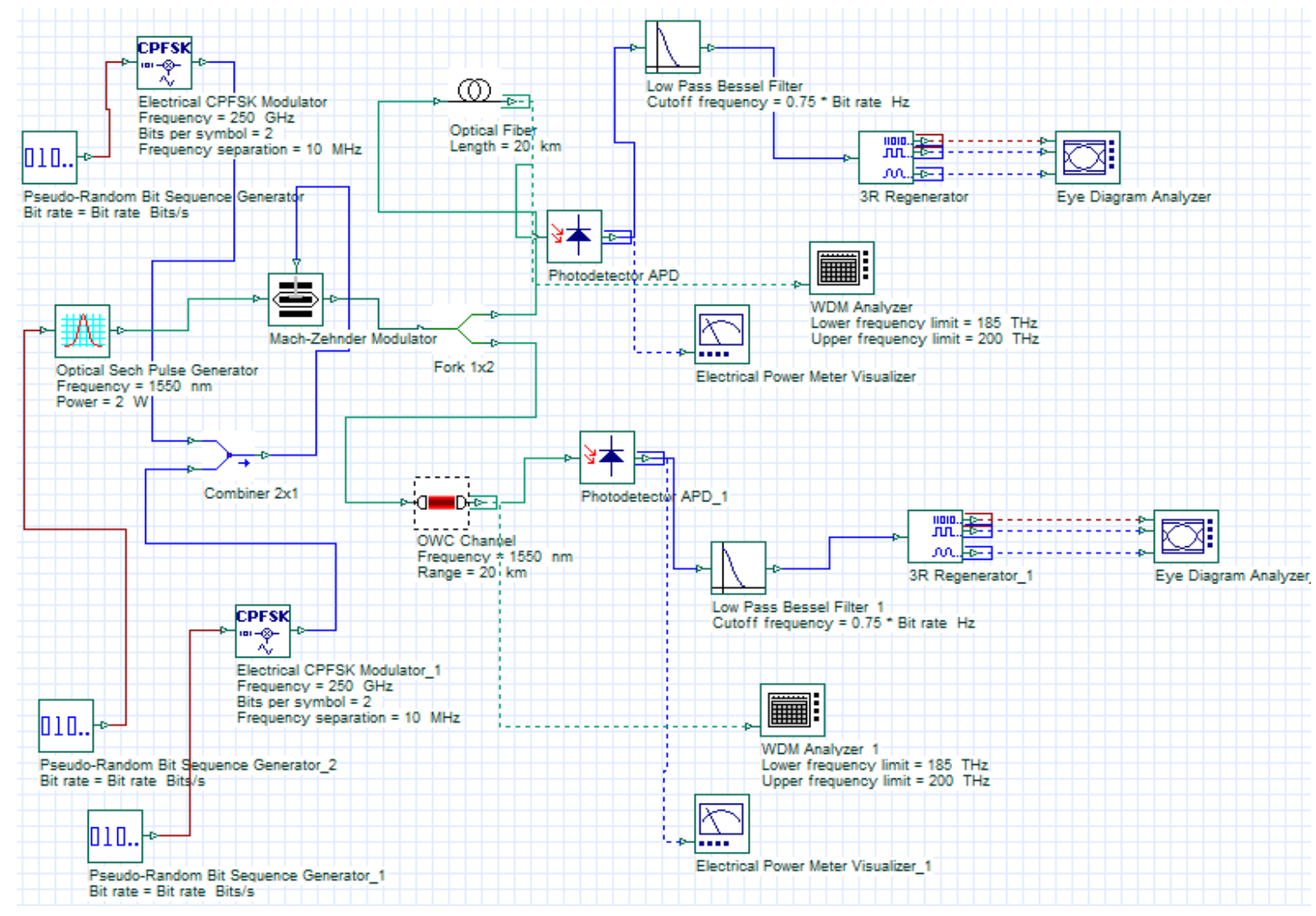

Figure 1. Proposed simulation model

\section{PERFORMANCE ANALYSIS WITH DISCUSSIONS}

We have simulated high modulated soliton power interaction with both optical fiber and optical wireless communication channels. There are different proposed modulation techniques are employed in the study, that are namely CPFSK, DPSK, PAM, QAM, FSK, OQFSK, and MSK. Optical signal/noise ratio at fiber/wireless communication channel is measured. As well as received electrical power and SNR at optical receiver are measured as in the series of Figures 2-14 based on variables in Table 1. Figure 2 has outlined OSNR at fiber/wireless channel, SNR at optical receiver and bits per symbol based CPFSK modulation technique. As bits per symbol increases leading to OSNR, and SNR decrease. It is observed that form Figure 3 , the effects of the increase of bits per symbol on the received power at optical receiver for both fiber/wireless communication channel. 
Table 1. Variable for proposed work [14]

\begin{tabular}{|c|c|}
\hline \multicolumn{2}{|c|}{ Optical Sech pulse generator } \\
\hline Parameter & Value \\
\hline Operating wavelength & $1550 \mathrm{~nm}$ \\
\hline Input power & $2 \mathrm{~W}$ \\
\hline \multicolumn{2}{|c|}{ Electrical modulators } \\
\hline Bits/symbol & $2,4,8,16,32,64$ \\
\hline Frequency separation & $10 \mathrm{MHz}$ \\
\hline Frequency & $250 \mathrm{GHz}$ \\
\hline \multicolumn{2}{|c|}{ Optical Wireless channel (OWC) } \\
\hline Attenuation (clear condition) & $0.2 \mathrm{~dB} / \mathrm{km}$ \\
\hline Range & $20 \mathrm{Km}$ \\
\hline Tx./Rx. Aperture diameter & $30 \mathrm{~cm}$ \\
\hline Beam divergence & $2 \mathrm{mrad}$ \\
\hline \multicolumn{2}{|c|}{ Fiber channel } \\
\hline Loss & $0.2 \mathrm{~dB} / \mathrm{Km}$ \\
\hline Dispersion & $16.75 \mathrm{ps} / \mathrm{nm} / \mathrm{Km}$ \\
\hline Range & $20 \mathrm{Km}$ \\
\hline \multicolumn{2}{|c|}{ MZM } \\
\hline Extinction ratio & $30 \mathrm{~dB}$ \\
\hline Symmetry factor & -1 \\
\hline \multicolumn{2}{|l|}{ 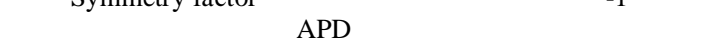 } \\
\hline Responsivity & $1 \mathrm{~A} / \mathrm{W}$ \\
\hline Dark current & $10 \mathrm{nA}$ \\
\hline \multicolumn{2}{|c|}{ LPBF } \\
\hline Loss & $0 \mathrm{~dB}$ \\
\hline Depth & $100 \mathrm{~dB}$ \\
\hline
\end{tabular}

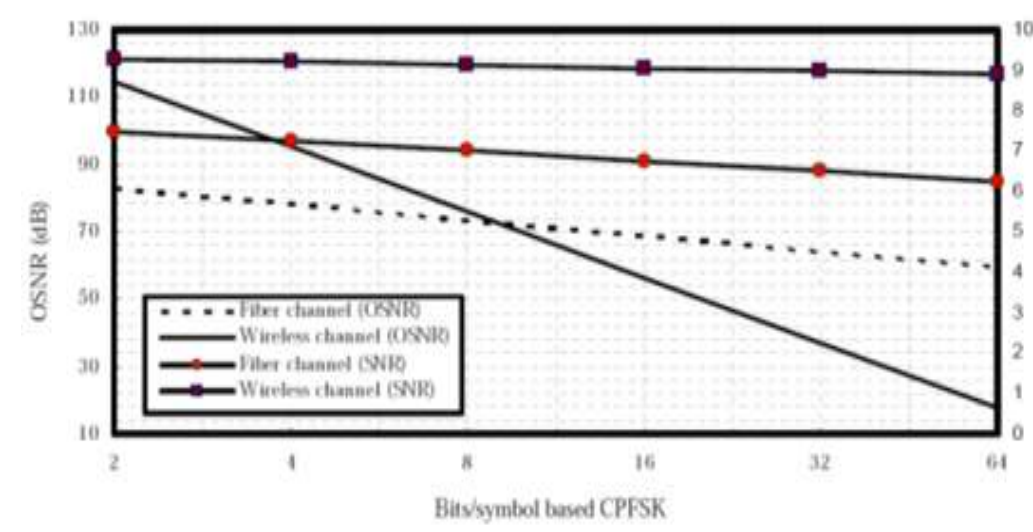

Figure 2. OSNR at fiber/wireless channel and SNR at optical receiver with bits/symbol based CPFSK modulation scheme for fiber/wireless communication channel

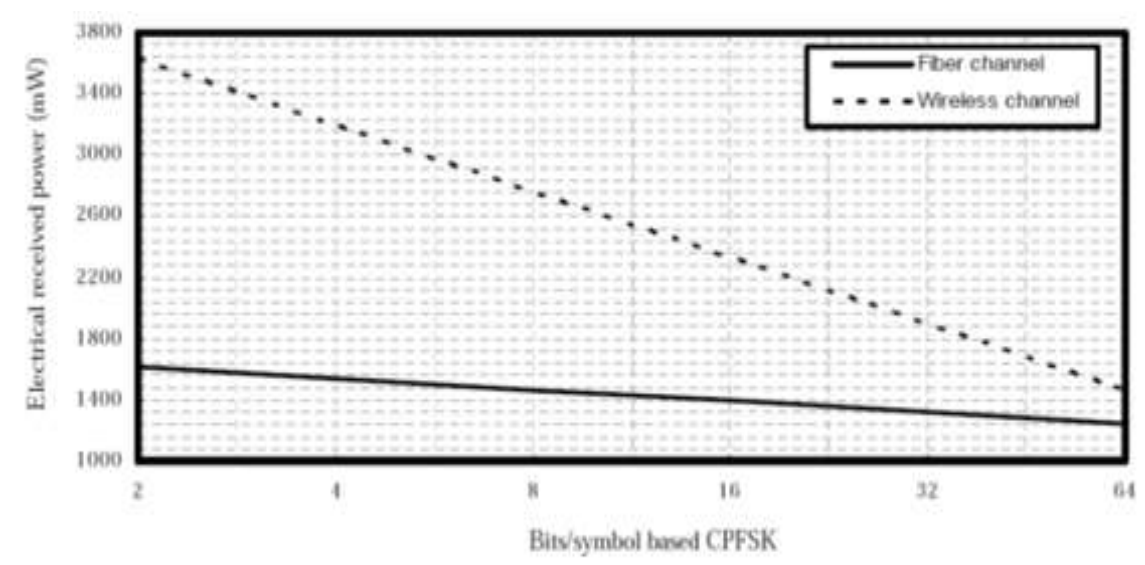

Figure 3. Received electrical power at photodetector with bits/symbol based CPFSK modulation scheme for fiber/wireless communication channel 


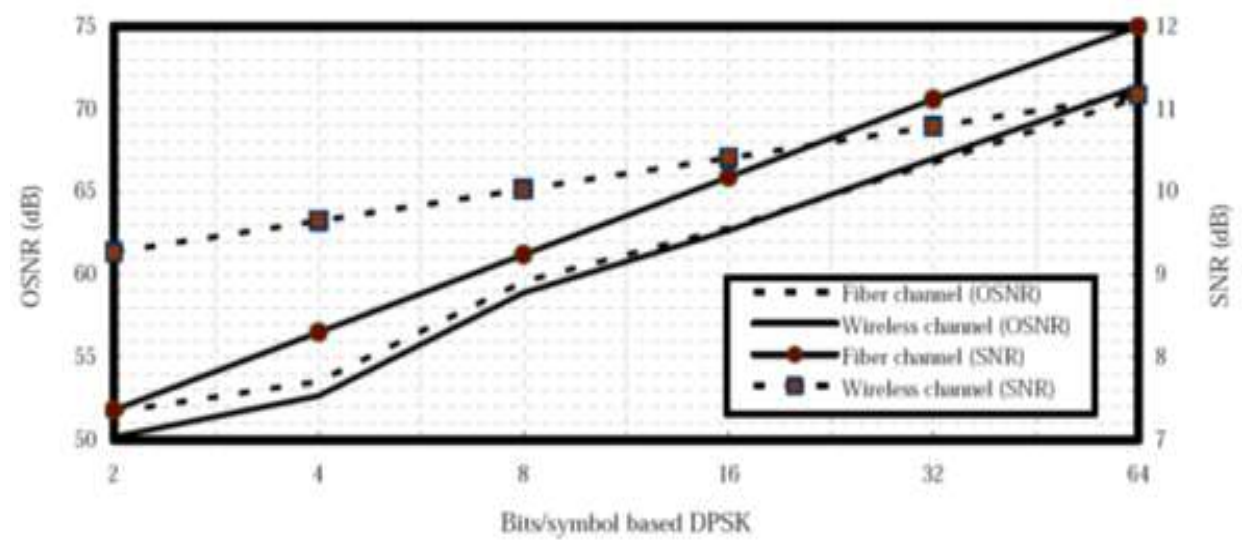

Figure 4. OSNR at fiber/wireless channel and SNR at optical receiver with bits per symbol based DPSK modulation scheme for fiber/wireless communication channel

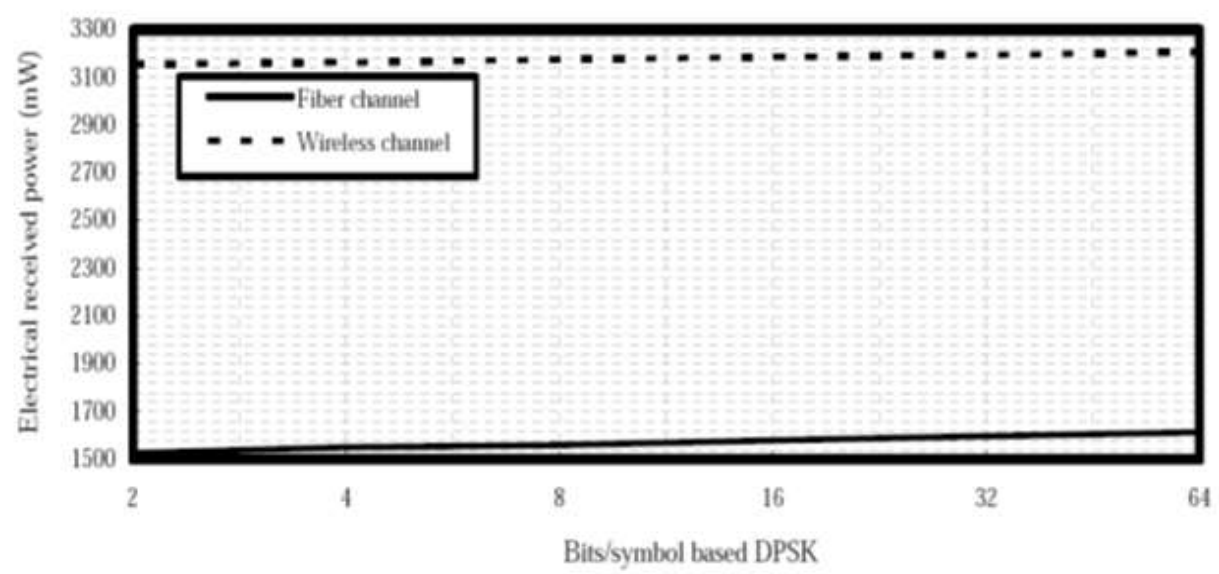

Figure 5. Received electrical power at photodetector with bits/symbol based DPSK modulation scheme for fiber/wireless communication channel

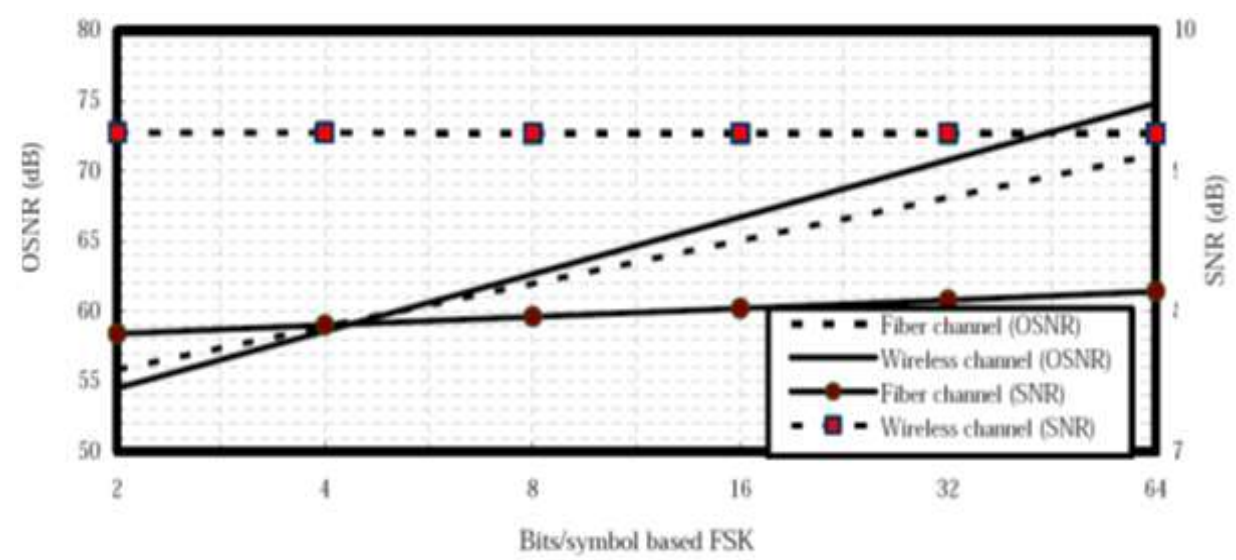

Figure 6. OSNR at fiber/wireless channel and SNR at optical receiver with bits/symbol based FSK modulation scheme for fiber/wireless communication channel 


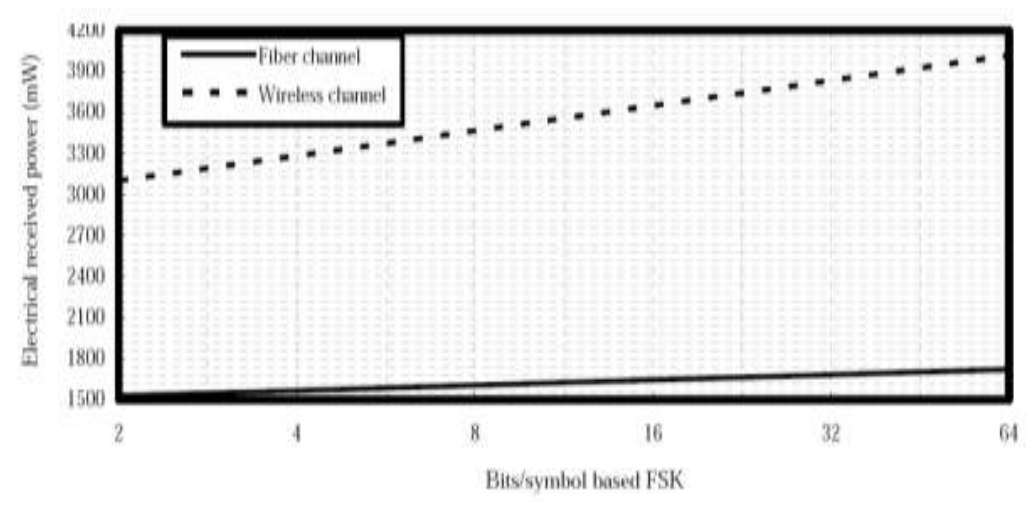

Figure 7. Received electrical power with bits/symbol based FSK modulation scheme for fiber/wireless channel

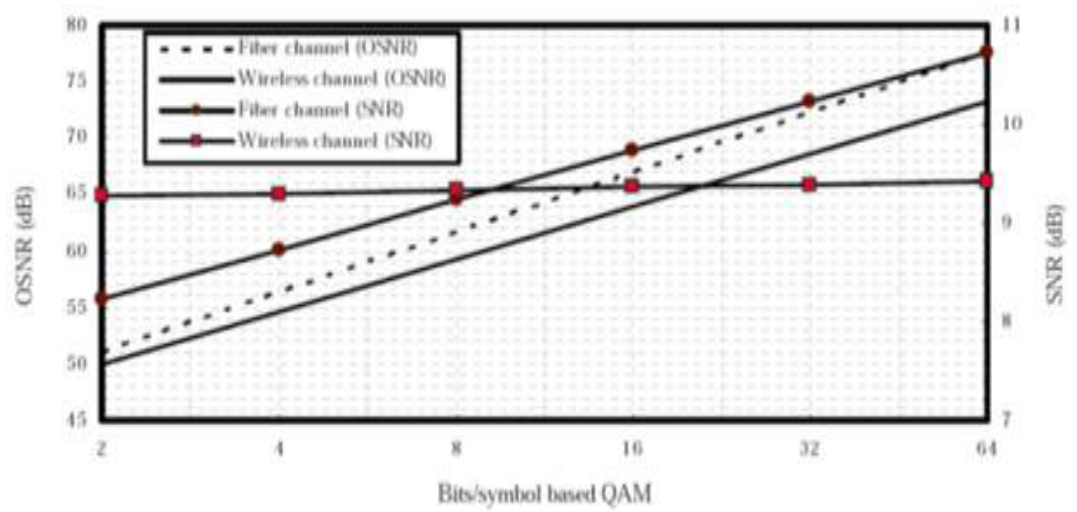

Figure 8. OSNR at fiber/wireless channel and SNR at optical receiver with bits/symbol based QAM modulation scheme for fiber/wireless communication channel

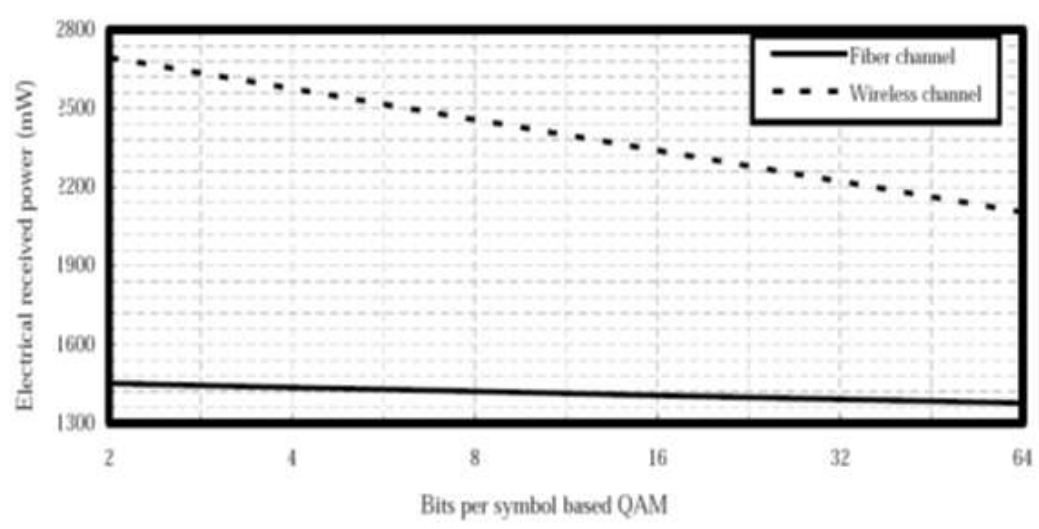

Figure 9. Received electrical power at photodetector against bits/symbol based QAM modulation scheme for fiber/wireless communication channel

On the other hand, it is observed that from Figures 4 and 5, the positive effects of increasing bits per symbol based DPSK modulation scheme on the optical signal/noise ratio (OSNR) at fiber/wireless channel, signal/noise ratio (SNR), and electrical received power at optical receiver. In the same way, it is clear that from Figures 6 and 7, the positive effects of increasing bits per symbol based FSK modulation scheme on the OSNR at fiber/wireless channel, SNR, and received electrical power at optical receiver. Figure 8 has presented the relation between OSNR, SNR and bits per symbol based QAM modulation scheme. As bits per 
symbol increases, leading to increase in both OSNR and SNR. On the other hand, the negative effects of increasing bits per symbol based QAM modulation scheme on electrical received power as clarified in Figure 9. Figure 10 has presented the relation between OSNR, signal to noise ratio and bits/symbol based PAM modulation scheme. As bits/symbol increases, leading to increase in both OSNR and SNR. On the other hand, the negative effects of increasing bits per symbol based PAM modulation scheme on electrical received power as clarified in Figure 11. As shown in Figure 12, the complete comparison for OSNR performance parameter for different proposed modulation techniques based both fiber/wireless communication channels. It is clear that CPFSK is more efficient and better performance than other proposed modulation schemes for both fiber/wireless channel.

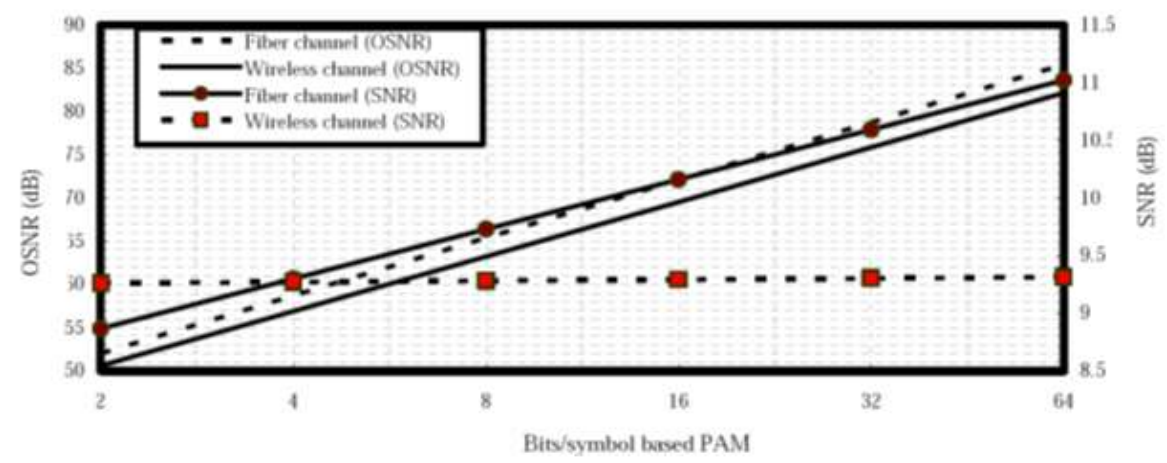

Figure 10. OSNR at fiber/wireless channel and SNR at optical receiver with bits/symbol based PAM modulation scheme for fiber/wireless communication channel

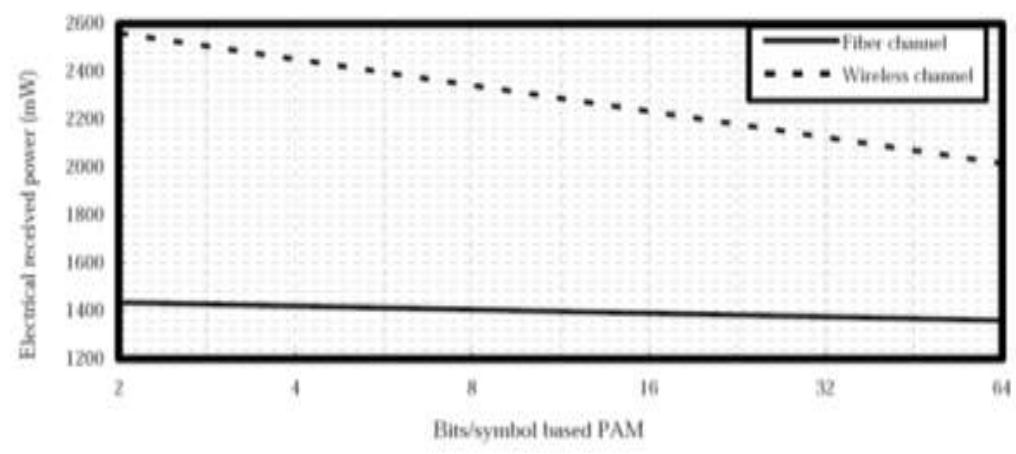

Figure 11. Received electrical power at photodetector with bits/symbol based PAM modulation scheme for fiber/wireless communication channel

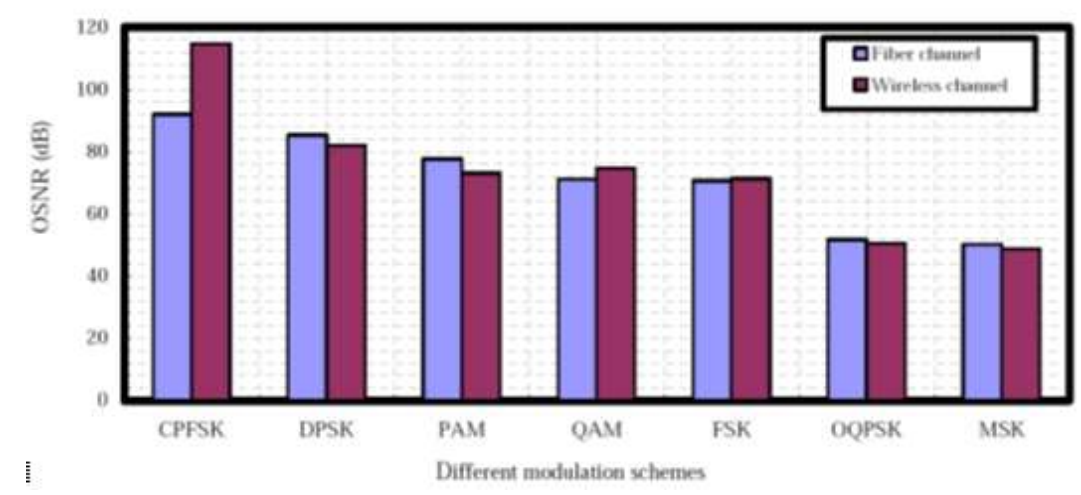

Figure 12. OSNR at fiber/wireless channel against various modulation schemes at optimum conditions 


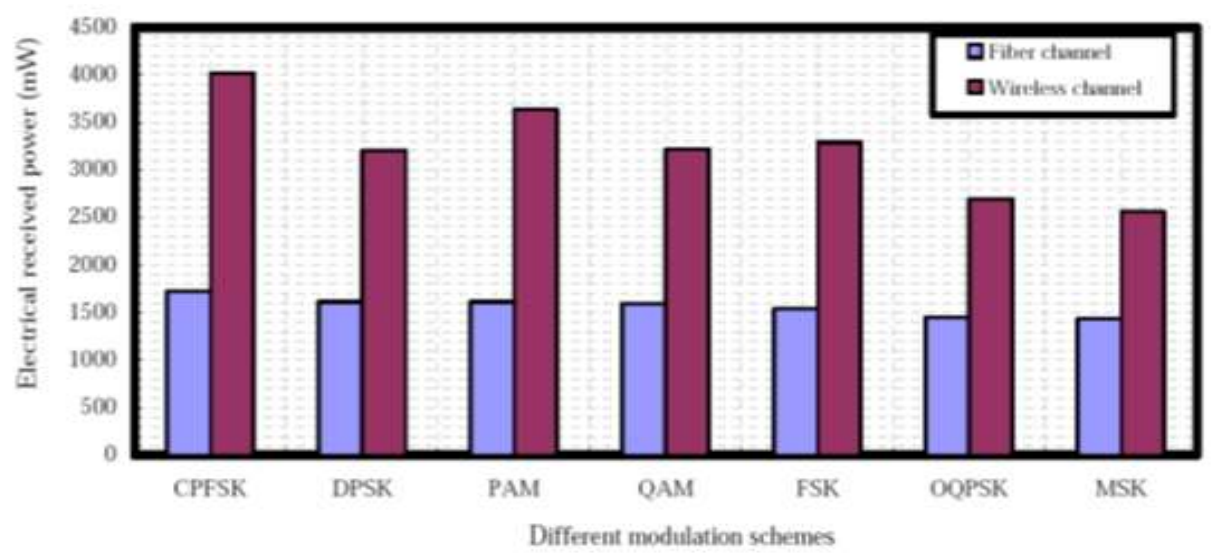

Figure 13. Electrical received power at optical receiver versus various modulation schemes at optimum conditions

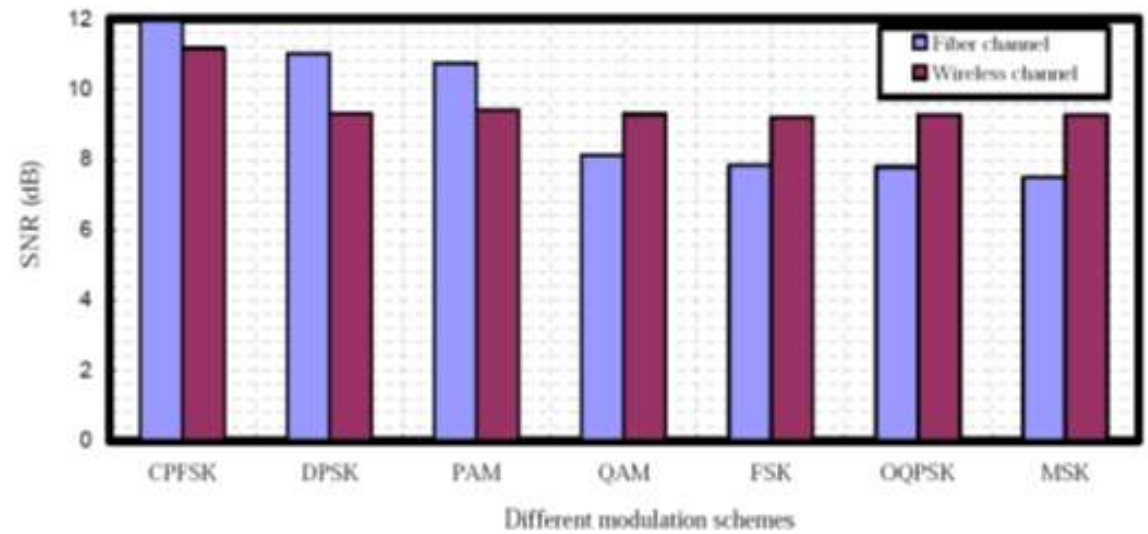

Figure 14. SNR at optical receiver against various modulation schemes at optimum conditions

It is clear that CPFSK is more efficient in optical wireless channel than fiber channel. As well as the electrical received power is upgraded by using CPFSK, PAM, FSK modulation schemes for optical wireless channel that fiber channel as clarified in Figure 13. Moreover, SNR is upgraded using CPFSK, DPSK, and PAM modulation schemes for optical fiber channel than optical wireless channel as clarified in Figure 14.

\section{CONCLUSION}

Various modulation schemes are employed with high soliton power transmission over fiber and wireless communication channels. It is found that the higher bits per symbol for different proposed modulation techniques, the higher OSNR, electrical received power, and SNR except for CPFSK modulation scheme. CPFSK modulation scheme has clarified better performance and more efficient than other proposed modulation techniques for both fiber/wireless communication channels. The received electrical power at optical receiver is enhanced by using proposed modulation techniques in optical wireless channel than fiber channel. It is evident that CPFSK, PAM, and DPSK are efficient in upgrading SNR at receiver for fiber channel over wireless channel. OSNR is enhanced by using CPFSK modulation scheme by enhancement percentage ratio ranges from $7.18 \%$ to $45.45 \%$ for optical fiber channel, and $28.45 \%$ to $57.6 \%$ for optical wireless communication channel. Electrical received power level is upgraded by using CPFSK modulation scheme that ranges from $6.4 \%$ to $16.85 \%$ in optical fiber channel, and its percentage enhancement ratio in received power level ranges from $9.58 \%$ to $36.23 \%$ for optical wireless communication channel. The percentage enhancement ratio in SNR value for CPFSK modulation over other proposed modulation techniques for optical fiber communication channel ranges from $8 \%$ to $37.39 \%$ and for optical wireless communication channel ranges from $15.6 \%$ to $17.63 \%$. 


\section{REFERENCES}

[1] F. Mitschke et al., "Soliton molecules for advanced optical telecommunications," The European Physical Journal, vol. 225, pp. 2453-2464, 2016, DOI: 10.1140/epjst/e2016-60023-1.

[2] IS Amiri , et al., "Transmission performances of solitons in optical wired link," Applied Computing and Informatics, vol. 13, pp.92-99, 2017.

[3] M. Y. Aldouri, et al., "Study of WDM Add and Drop in Soliton Effects in Free Space Optics," International Journal on Future Revolution in Computer Science \& Communication Engineering, vol. 3, no. 12, pp. 412-420, 2017, available @ http://www.ijfrcsce.org.

[4] M.G. Prabha and D. H. Margaret, "Analysis of Soliton Interaction with Higher Order Effects in Erbium-Doped Fiber," Asian Journal of Applied Science and Technology (AJAST), vol. 2, no. 2, pp. 591-598, 2018.

[5] M. S. Mani Rajan, A. Mahalingam, "Nonautonomous solitons in modified inhomogeneous Hirota equation: soliton control and soliton interaction," Nonlinear Dyn., vol. 79, pp. 2469-2484, 2015.

[6] M. S. Mani Rajan, A. Mahalingam, "Multi-soliton propagation in a generalized inhomogeneous nonlinear Schrödinger Maxwell-Bloch system with loss/gain driven by an external potential," J. Math. Phys., vol. 54, pp. 043514-043527, 2013.

[7] Mahalingam, et al., "Propagation of dispersion nonlinearity managed solitons in an inhomogeneous erbium doped fiber system," J. Phys. A Math. Theor., vol. 42, p. 165101, 2009.

[8] E. Poutrina, G. P. Agrawal, "Design Rules For Dispersion-Managed Soliton Systems," Optics Communications, vol. 206, pp. 193-200, 2002.

[9] M.G. Prabha1, et al., “Analysis Of Femtosecond Soliton Interaction In Erbium-Doped Fiber,” International Journal of Advance Engineering and Research Development, vol. 5, Special no. 8, pp. 1-8, 2018.

[10] S. Subi, and G. b. Lakshmi, "Optical Solitons Simulation Using DSF and Optical Pulse Generator in Single Mode Optical Fiber," International Journal of Science and Research (IJSR), ISSN (Online): 2319-7064, vol. 4, no. 2, pp. 254-258, 2015.

[11] M. Arora and G. Pandove, "Simulated Circuit for Generation of $40 \mathrm{GHz}$ Soliton Train," International Journal of Emerging Trends in Electrical and Electronics, vol. 5, no. 2, pp. 73-76, 2013.

[12] J. Adaikala Susai, and S. Robinson, "Analyzing the Transmission Performance of the Optical Soliton System," International Journal of Emerging Technology and Advanced Engineering, vol. 3, no. 2, pp. 137-140, 2013.

[13] S. Praveen Chakkravarthy, et al., "Ultra high transmission capacity based on optical first order soliton propagation systems," Results in Physics, vol. 12, pp. 512-513, 2019.

[14] OptiSystem Tutorials, Optical Communication System Design Software version 13, vol. 1, pp. 1-500, 2014, https://dru5cjyjifvrg.cloudfront.net/wpcontent/uploads/2015/03/OptiSystem_Tutorials_Volume_1.pdf.

[15] Ahmed Nabih Zaki Rashed, et al., "Transmission Performance Simulation Study Evaluation for High Speed Radio Over Fiber Communication Systems," Wireless Personal Communications Journal, vol. 103, no. 2, pp. 1765-1779, 2018, https://doi.org/10.1007/s11277-018-5879-y.

[16] Ahmed Nabih Zaki Rashed, Mohammed Salah F. Tabbour "Best candidate integrated technology for low noise, high speed, and wide bandwidth based transimpedance amplifiers in optical computing systems and optical fiber applications" International Journal of Communication Systems, vol. 31, no. 17, paper id: e3801, Nov. 2018, https://doi.org/10.1002/dac.3801.

[17] Ahmed Nabih Zaki Rashed, et al., "20 Gb/s Hybrid CWDM/DWDM for Extended Reach Fiber to the Home Network Applications," Proc. Natl. Acad. Sci., India, Sect. A Phys. Sci, vol. 89, no. 4, pp. 653-662, 2019, https://doi.org/10.1007/s40010-018-0526-2.

[18] C.S. Boopathi, et al., "Design of human blood sensor using symmetric dual core photonic crystal fiber," Results in Physics, vol. 11, pp. 964-965, 2018.

[19] S. Praveen Chakkravarthy, et al., "Ultra high transmission capacity based on optical first order soliton propagation systems," Results in Physics, vol. 12, pp. 512-513, 2019.

[20] Kawsar Ahmed, et al., "Design of D-shaped elliptical core photonic crystal fiber for blood plasma cell sensing application," Results in Physics, vol. 12, pp. 2021-2025, 2019.

[21] T.V. Ramana, et al., "Numerical analysis of circularly polarized modes in coreless photonic crystal fiber," Results in Physics, vol. 13, Article 102140, 2019, https://doi.org/10.1016/j.rinp.2019.02.076.

[22] Ahmed Nabih Zaki Rashed, et al., "The switching of optoelectronics to full optical computing operations based on nonlinear metamaterials," Results in Physics, vol. 13, Article 102152, 2019, https://doi.org/10.1016/j.rinp.2019.02.088.

[23] IS Amiri, et al., "High-Speed Light Sources in High-Speed Optical Passive Local Area Communication Networks," Journal of Optical Communications, vol. 0, no. 0, Published Online: 20 2019, https://doi.org/10.1515/joc-20190070 .

[24] Ahmed Nabih Zaki Rashed, et al., "Performance enhancement of overall LEO/MEO intersatellite optical wireless communication systems," International Journal of Satellite Communications and Networking, vol. 38, no. 1, pp. 31-40, 2020. DOI: 10.1002/sat.1306.

[25] IS Amiri, et al., "Spatial Continuous Wave Laser and Spatiotemporal VCSEL for High-Speed Long Haul Optical Wireless Communication Channels," Journal of Optical Communications, vol. 0, no. 0, Published Online: 24 April 2019, https://doi.org/10.1515/joc-2019-0061.

[26] IS Amiri, et al., "Average Power Model of Optical Raman Amplifiers Based on Frequency Spacing and Amplifier Section Stage Optimization," Journal of Optical Communications, vol. 0, no. 0, Published Online: 4 May 2019, https://doi.org/10.1515/joc-2019-0081. 
[27] IS Amiri, et al., "Temperature effects on characteristics and performance of near-infrared wide bandwidth for different avalanche photodiodes structures," Results in Physics, vol. 14, Article 102399, September 2019, https://doi.org/10.1016/j.rinp.2019.102399.

[28] S. Malathy, K et al., "Upgrading Superior Operation Performance Efficiency of Submarine Transceiver Optical Communication Systems Toward Multi Tera Bit per Second," Computer Communications Journal, vol. 146, pp. 192-200, 2019, http://doi.org./10.1016/j.comcom.2019.08.009.

[29] IS Amiri, Ahmed Nabih Zaki Rashed, "Numerical investigation of V shaped three elements resonator for optical closed loop system," Indonesian Journal of Electrical Engineering and Computer Science (IJEECS), vol. 16, no. 3, pp. 1392-1397, 2019, DOI: 10.11591/ijeecs.v16.i3.pp1392-1397.

[30] Ahmed Nabih Zaki Rashed, Mohamed Salah F. Tabbour "The Engagement of Hybrid Dispersion Compensation Schemes Performance Signature for Ultra Wide Bandwidth and Ultra Long Haul Optical Transmission Systems," Wireless Personal Communications Journal, Published online 19 August, https://doi.org/10.1007/s11277-01906687-2.

[31] Ahmed Nabih Zaki Rashed, et al., "The effect of using different materials on erbium-doped fiber amplifiers for indoor applications," Results in Physics, vol. 15, paper id: 102650, Dec. 2019, https://doi.org/10.1016/j.rinp.2019.102650.

[32] IS Amiri and Ahmed Nabih Zaki Rashed, "Power Enhancement of the U-shape Cavity Microring Resonator Through Gap and Material Characterizations," Journal of Optical Communications, vol. 0, no. 0, Published Online: 19 Oct. 2019, https://doi.org/10.1515/joc-2019-0108.

[33] IS Amiri, P et al., "The Engagement of Hybrid Ultra High Space Division Multiplexing with Maximum Time Division Multiplexing Techniques for High-Speed Single-Mode Fiber Cable Systems," Journal of Optical Communications, vol. 0, no. 0, Published Online: 19 Oct. 2019, https://doi.org/10.1515/joc-2019-0205.

[34] IS Amiri, et al., "Polar Polarization Mode and Average Radical Flux Intensity Measurements Based on All Optical Spatial Communication Systems," Journal of Optical Communications, vol. 0, no. 0, Published Online: 19 Oct. 2019, https://doi.org/10.1515/joc-2019-0159.

[35] S. Sivaranjani, et al., "Performance Evaluation of Bidirectional Wavelength Division Multiple Access Broadband Optical Passive Elastic Networks Operation Efficiency," Journal of Optical Communications, vol. 0, no. 0, Published Online: 24 Oct. 2019, https://doi.org/10.1515/joc-2019-0175.

[36] IS Amiri, et al., "High-Speed Transmission Circuits Signaling in Optical Communication Systems," Journal of Optical Communications, vol. 0, no. 0, Published Online: 9 Nov. 2019, https://doi.org/10.1515/joc-2019-0197.

[37] IS Amiri, et al., "Technical Specifications of the Submarine Fiber Optic Channel Bandwidth/Capacity in Optical Fiber Transmission Systems," Journal of Optical Communications, vol. 0, no. 0, Published Online: 9 Nov. 2019, https://doi.org/10.1515/joc-2019-0226.

[38] Hazem M. El-Hageen, et al., "RZ Line Coding Scheme With Direct Laser Modulation for Upgrading Optical Transmission Systems," Open Eng. Journal, vol. 10, no. 1, pp. 546-551, 2020, https://doi.org/10.1515/eng-20200066.

[39] Aadel M. Alatwi, et al., "Wavelength division multiplexing techniques based on multi transceiver in low earth orbit intersatellite systems," Journal of Optical Communications, vol. 0, no. 0, Published Online: 29 June 2020, https://doi.org/10.1515/joc-2019-0171.

[40] Hazem M. El-Hageen, et al., "Different modulation schemes for direct and external modulators based on various laser sources," Journal of Optical Communications, vol. 0, no. 0, Published Online: 25 July 2020, https://doi.org/10.1515/joc-2020-0029.

[41] Hazem M. El-Hageen, et al., "High-speed signal processing and wide band optical semiconductor amplifier in the optical communication systems," Journal of Optical Communications, vol. 0, no. 0, Published Online: 3 August 2020, https://doi.org/10.1515/joc-2020-0070.

[42] Aadel M. Alatwi, et al., "Beam divergence and operating wavelength bands effects on free space optics communication channels in local access networks," Journal of Optical Communications, vol. 0, no. 0, Published Online: 8 August 2020, https://doi.org/10.1515/joc-2019-0276.

[43] Aadel M. Alatwi, Ahmed Nabih Zaki Rashed, "Hybrid CPFSK/OQPSK modulation transmission techniques' performance efficiency with RZ line coding-based fiber systems in passive optical networks," Indonesian Journal of Electrical Engineering and Computer Science (IJEECS), vol. 21, no. 1, pp. 263-270, 2021, DOI: 10.11591/ijeecs.v21.i1. pp263-270.

[44] Aadel M. Alatwi, Ahmed Nabih Zaki Rashed, "An analytical method with numerical results to be used in the design of optical slab waveguides for optical communication system applications," Indonesian Journal of Electrical Engineering and Computer Science (IJEECS), vol. 21, no. 1, pp. 278-286, 2021, ISSN: 2502-4752, DOI: 10.11591/ijeecs.v21.i1.pp278-286.

[45] Aadel M. Alatwi, Ahmed Nabih Zaki Rashed, "Conventional doped silica/fluoride glass fibers for low loss and minimum dispersion effects," Indonesian Journal of Electrical Engineering and Computer Science (IJEECS), vol. 21, no. 1, pp. 287-295, 2021, DOI: 10.11591/ijeecs.v21.i1.pp287-295. 